\title{
SOLDAGEM POR EXTRUSÃO EM CHAPAS DE POLIETILENO DE ALTA DENSIDADE - AVALIAÇÃO SOB UMA PERSPECTIVA NAVAL*
}

\author{
Felipe Lacerda Giro ${ }^{1}$ \\ Guilherme Zeemann Pinho Emygdio² \\ Alexandre Teixeira de Pinho Alho ${ }^{3}$ \\ Marta Cecilia Tapia Reyes ${ }^{4}$
}

\begin{abstract}
Resumo
Atualmente, a soldagem por extrusão de peças semi-acabadas (chapas) em PEAD tem se mostrado como uma solução atraente para a fabricação de pequenas embarcações de serviço. Neste sentido, a qualidade da soldagem torna-se um elemento fundamental para a garantia da integridade estrutural da embarcação. Neste trabalho são apresentados os resultados da análise da influência de diferentes fatores na qualidade da soldagem por extrusão de chapas de polietileno de alta densidade. Os fatores analisados envolveram o aporte de calor, a preparação do chanfro, a velocidade de soldagem e a pigmentação do fio de solda. A influência de tais fatores na qualidade da solda foi avaliada tendo como referência os resultados de ensaios de flexão em corpos de prova.
\end{abstract}

Palavras-chave: PEAD; Soldagem; Extrusão; Naval.

\section{EXTRUSION WELDING IN HIGH-DENSITY POLYETHYLENE SHEETS - EVALUATION FROM A MARINE POINT OF VIEW}

\section{Abstract}

Currently, extrusion welding of semi-finished HDPE parts (plates) has proven to be an attractive solution for the manufacturing of small service boats. In this sense, welding quality becomes a key element for ensuring the structural integrity of the boat. This paper presents the results of an analysis of the influence of different factors on the quality of extrusion welding of high density polyethylene sheets. The factors analyzed involved the heat input, the preparation of the bevel, the welding speed and the welding wire pigmentation. The influence of such factors on weld quality was assessed with reference to the results of bending tests on specimens.

Keywords: HDPE; Welding; Extrusion; Marine.

1 Graduando em Engenharia Naval e Oceânica pela Universidade Federal do Rio de Janeiro, UFRJ, Brasil;

2 Engenheiro de Materiais pela Universidade Federal do Rio de Janeiro, Consultor Técnico da TECMETAL, Rio de Janeiro, RJ, Brasil;

3 Doutor em Engenharia Oceânica, Professor Adjunto da Universidade Federal do Rio de Janeiro, UFRJ, Brasil;

4 Doutora em Engenharia Oceânica, Professora Associada da Universidade Federal do Rio de Janeiro, UFRJ, Brasil. 


\section{INTRODUÇÃO}

A utilização de materiais plásticos na construção de embarcações de pequeno porte teve início há mais de 50 anos com o lançamento das primeiras embarcações fabricadas em polímero reforçado com fibra de vidro (PRFV). O advento do uso de PRFV revolucionou a indústria náutica devido a sua grande disponibilidade, baixo custo e fácil manipulação. Apesar das inúmeras vantagens oferecidas em relação aos materiais tradicionalmente adotados, o uso dos PRFV como material base para a fabricação de cascos impõe o uso de moldes ou formas, o que representa uma limitação importante. O elevado custo dos moldes e formas para a laminação de embarcações em PRFV restringe a realização de alterações no projeto, particularmente nos componentes de maior porte, tais como casco, cabine e console.

Materiais termoplásticos têm sido largamente utilizados na indústria náutica para a confecção de pequenos componentes e acessórios, tais como cunhos e moitões. Todavia, sua aplicação para a fabricação de cascos surgiu apenas recentemente, tendo sido iniciada pela fabricação de pequenas embarcações, tais como caiaques, em PEAD - polietileno de alta densidade, através do processo de rotomoldagem. $O$ emprego de termoplásticos para a fabricação de embarcações de pequeno porte tem crescido gradativamente, já sendo encontradas no mercado embarcações de até 24 pés fabricadas em PEAD rotomoldado.

Entretanto, a utilização do processo de rotomoldagem resulta nas mesmas restrições observadas quanto a alterações no projeto, devido, igualmente, ao elevado custo dos moldes. A demanda pela customização dos projetos, bem como pelo desenvolvimento de estruturas cada vez maiores e mais complexas resultou na adoção da soldagem como alternativa para a fabricação de embarcações em materiais termoplásticos. Atualmente, a soldagem por extrusão de peças semiacabadas (chapas) em PEAD tem se mostrado como uma solução atraente para a fabricação de pequenas embarcações de serviço. Neste sentido, a qualidade da soldagem torna-se um elemento fundamental para a garantia da integridade estrutural da embarcação.

Neste trabalho são apresentados os resultados da análise da influência de diferentes fatores na qualidade da soldagem por extrusão de chapas de polietileno de alta densidade. Os fatores analisados envolveram o aporte de calor, a preparação do chanfro, a velocidade de soldagem e a pigmentação do fio de solda. A influência de tais fatores na qualidade da solda foi avaliada tendo como referência os resultados de ensaios de flexão em corpos de prova.

\section{MATERIAIS E MÉTODOS}

\subsection{Materiais e equipamentos}

Os corpos de prova testados foram confeccionados a partir de chapas laminadas de polietileno de alta densidade (PEAD) de $12 \mathrm{~mm}$ de espessura, tendo por material base a resina BS002W, fabricada pela empresa Braskem ${ }^{\circledR}$. Os chanfros para os cordões de solda foram usinados a $60^{\circ}$ em uma máquina fresadora CNC. A soldagem dos corpos de prova foi executada com uma extrusora marca LEISTER ${ }^{\circledR}$, modelo Fusion 3. Os fios de solda utilizados foram confeccionados com a mesma resina das chapas, sendo utilizadas duas configurações, a saber: natural e com pigmentação em preto, esta última com aditivos anti-chama e anti-UV. 


\subsection{O Processo de Soldagem por Extrusão}

O processo de soldagem dos corpos de prova foi realizado de acordo com os requisitos estabelecidos pela norma DVS 2207-4 - Welding of Thermoplastics Extrusion welding of pipes, piping parts and panels- Processes and Requirements [2]. A soldagem por extrusão é caracterizada como um processo manual ou parcialmente mecanizado. $O$ processo é realizado a partir de um material de adição sob a forma de fio, ou granulado,o qual é completamente fundido e plastificado pela extrusora. Diferentes bicos de soldagem são usados de acordo com a geometria do chanfro e servem para depositar e plastificar o material de adição no espaço do chanfro. Neste trabalho foi adotado o ângulo do chanfro de $60^{\circ}$ com o espaçamento de $1 \mathrm{~mm}$ entre as chapas bases.

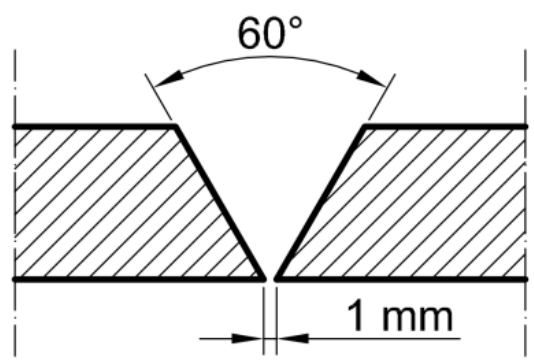

Figura 1 Chanfro de solda em $\mathrm{V}, 60^{\circ}$, espaçamento de $1 \mathrm{~mm}$, adotado neste trabalho.

Para realizar uma solda de qualidade as faces do chanfro não podem estar avariadas, degradadas ou contaminadas. O procedimento, chamado de preparação ou higienização, envolve, preliminarmente, a realização de uma raspagem das superfícies do chanfro e sua posterior limpeza com álcool isopropílico, de modo a garantir a remoção quaisquer impurezas.

\subsection{Condições de Soldagem}

As variáveis essenciais cuja influência foi analisada neste trabalho foram:

- O uso ou não de pigmentação no fio de solda (fio natural ou pigmentado);

- O aporte de calor, através da variação da temperatura do material base e/ou do fio de solda; bem como da velocidade de soldagem (aporte de calor baixo ou alto);

- A execução ou não de preparação prévia (higienizada ou sem higienização).

Os corpos de provas foram confeccionados a partir de chapas soldadas, apresentando $150 \mathrm{~mm} \times 300 \mathrm{~mm}$ de dimensões. No total foram confeccionados 8 conjuntos de corpos de provas. As configurações dos parâmetros adotados na soldagem das chapas de teste são apresentadas na Tabela 1. 
Tabela 1 Configurações dos parâmetros de soldagem das chapas de teste.

\begin{tabular}{|c|c|c|c|c|c|c|c|c|c|}
\hline \multirow[b]{2}{*}{ Grupo } & \multirow[b]{2}{*}{$\begin{array}{c}\text { Material de } \\
\text { solda }\end{array}$} & \multicolumn{4}{|c|}{ Temperatura } & \multirow[b]{2}{*}{ Higienização } & \multirow[b]{2}{*}{ 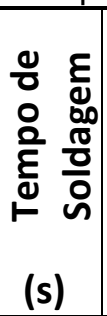 } & \multirow{2}{*}{ 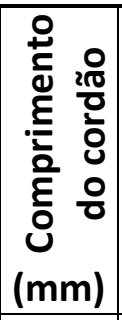 } & \multirow{2}{*}{ 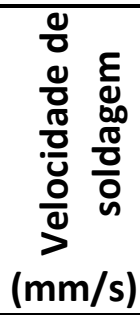 } \\
\hline & & $\begin{array}{c}0 \\
n \\
\tilde{D} \\
\\
\left({ }^{\circ} \mathrm{C}\right)\end{array}$ & 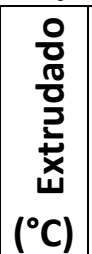 & 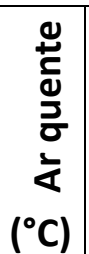 & 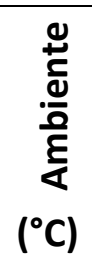 & & & & \\
\hline 1 & Natural & 117 & 178 & 193 & 36.8 & Higienizado & 105 & 300 & 2,9 \\
\hline 2 & Natural & 78 & 108 & 128 & 36.8 & Higienizac & 100 & 300 & 3,0 \\
\hline 3 & Natural & 127 & 166 & 182 & 36.8 & Não & 105 & 300 & 2,9 \\
\hline 4 & Pigmentada & 110 & 178 & 190 & 36.8 & Higienizado & 80 & 250 & 3,1 \\
\hline 5 & Pigmentada & 83 & 118 & 130 & 36.8 & Higienizado & 85 & 250 & 2,9 \\
\hline 6 & Pigmentada & 128 & 183 & 191 & 36.8 & Não & 110 & 300 & 2,7 \\
\hline 7 & Pigmentada & 160 & 168 & 190 & 36.8 & Higienizado & 59 & 300 & 5,1 \\
\hline 8 & Pigmentada & 93 & 94 & 130 & 36.8 & Higienizado & 60 & 300 & 5,0 \\
\hline
\end{tabular}

\subsection{Ensaios de Flexão}

A partir de cada chapa de teste, foram produzidos seis corpos de prova para a realização dos ensaios de flexão de face. Para fins de comparação, também foram confeccionados corpos de prova exclusivamente a partir do material de base, bem como do material do fio de solda pigmentado. Nestes casos, no entanto, apenas três corpos de prova forma produzidos.

De acordo com a norma DVS 2203-5 [1], o ensaio de flexão é realizado com a configuração de três apoios, composto por dois cilindros e um cutelo, tal como ilustrado na Figura 2. Ao se deslocar, o cutelo provoca a flexão do corpo de prova. A configuração apresentada na Figura 2 corresponde ao arranjo específico para as chapas de $12 \mathrm{~mm}$ de espessura adotadas como referência para a realização deste trabalho.

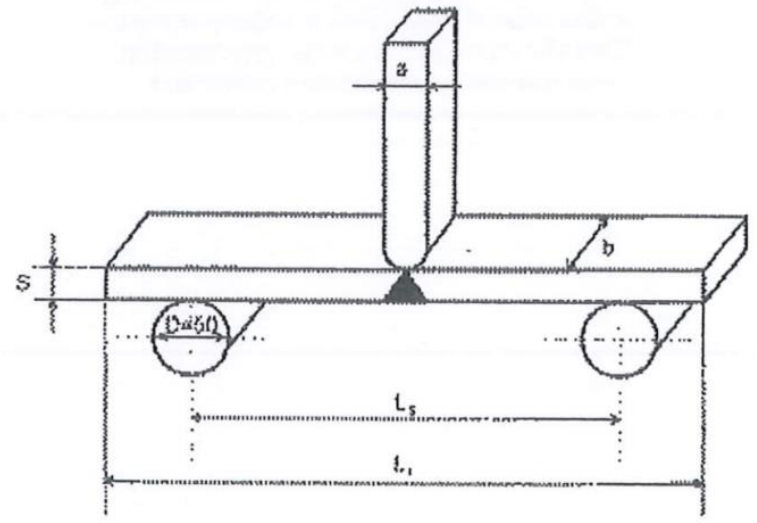

Figura 2 Representação esquemática do ensaio de flexão

Sendo:

$s=\quad$ espessura da amostra de teste $=12 \mathrm{~mm}$;

$b=\quad$ largura da amostra de teste $=20 \mathrm{~mm}$;

$L_{1}=$ comprimento total da amostra $=200 \mathrm{~mm}$;

$L_{S}=\quad$ distância entre os eixos dos cilindros $=100 \mathrm{~mm}$;

$a=\quad$ diâmetro do cutelo $=12,5 \mathrm{~mm}$;

$D=\quad$ diâmetro dos cilindros $=12,5 \mathrm{~mm}$. 
A norma DVS 2203-5 [1] estabelece como critério de aceitação, para a configuração do presente ensaio de flexão, um deslocamento máximo $70 \mathrm{~mm}$ do cutelo sem a ocorrência de ruptura. O ensaio deve ser interrompido quando o deslocamento máximo do cutelo é atingido ou quando ocorrer o trincamento ou a ruptura do corpo de prova. A velocidade de deslocamento do cutelo é de $50 \mathrm{~mm} / \mathrm{min}$. Os resultados obtidos nos ensaios incluem a variação da carga aplicada em relação ao deslocamento do cutelo.

\section{RESULTADOS E DISCUSSÃO}

A Figura 3 ilustra o aspecto dos corpos de prova de flexão após o teste, sendo mostrados os diferentes comportamentos observados.

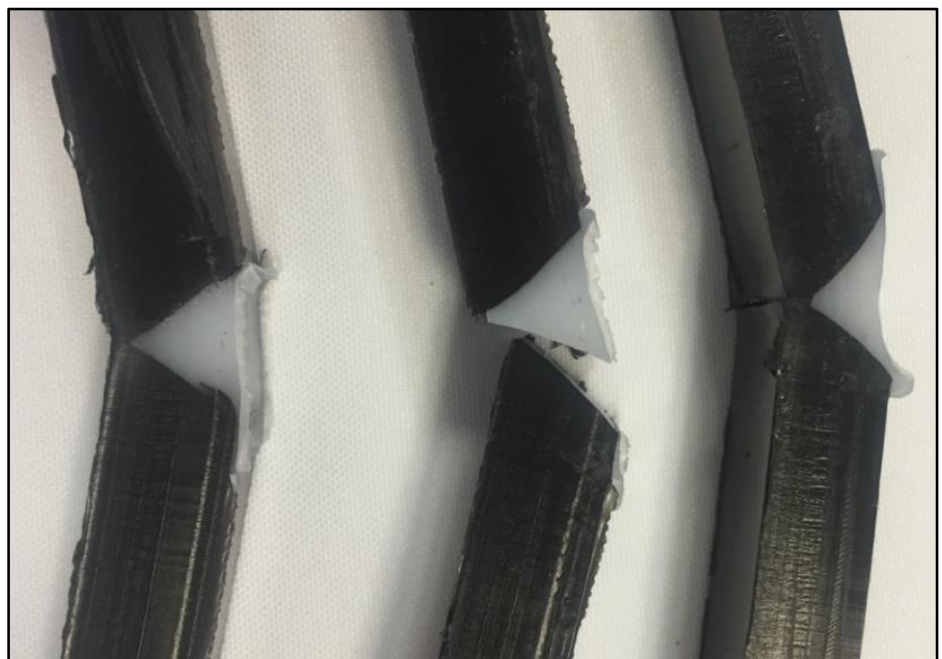

Fio de solda natural: À esquerda, Grupo 1, cordão de solda natural, aporte de calor adequado, higienizada, velocidade de soldagem adequada; Ao centro, Grupo 2, cordão de solda natural, baixo aporte de calor, higienizada, velocidade de soldagem adequada; À direita, Grupo 3, cordão de solda natural, aporte de calor adequado, não higienizada, velocidade de soldagem adequada.

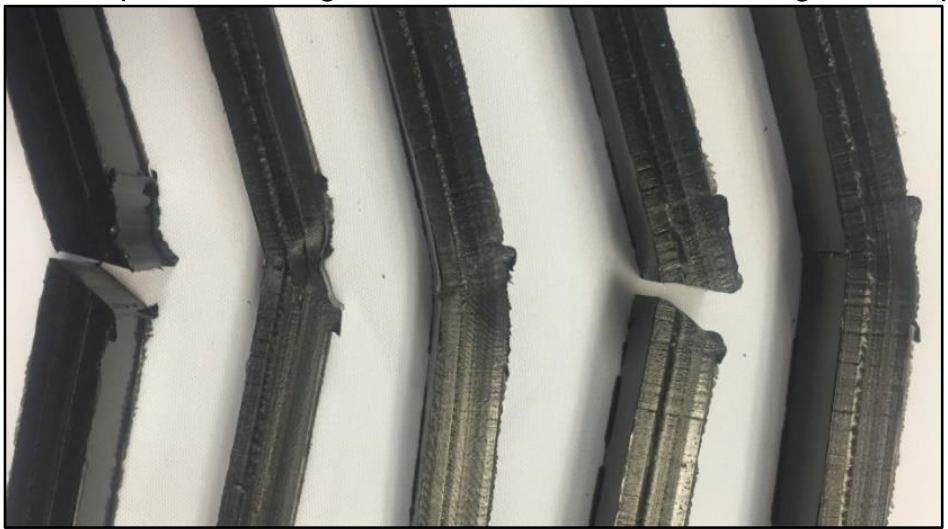

Fio de solda pigmentado, da esquerda para direita: Grupo 8, cordão de solda pigmentado, baixo aporte de calor, higienizada, velocidade de soldagem alta; Grupo 7, cordão de solda pigmentado, aporte de calor adequado, higienizada, velocidade de soldagem alta; Grupo 6, cordão de solda pigmentado, aporte de calor adequado, não higienizada, velocidade de soldagem adequada; Grupo 5, cordão de solda pigmentado, baixo aporte de calor, higienizada, velocidade de soldagem adequada; Grupo 4, cordão de solda pigmentado, aporte de calor adequado, higienizada, velocidade de soldagem adequada;

Figura 3.Aspecto dos corpos de prova de flexão testados.

A Tabela 2 apresenta os resultados dos ensaios de flexão. Na Figura 4, os resultados obtidos são apresentados em forma gráfica. 
Tabela 2.Resultados dos ensaios de flexão.

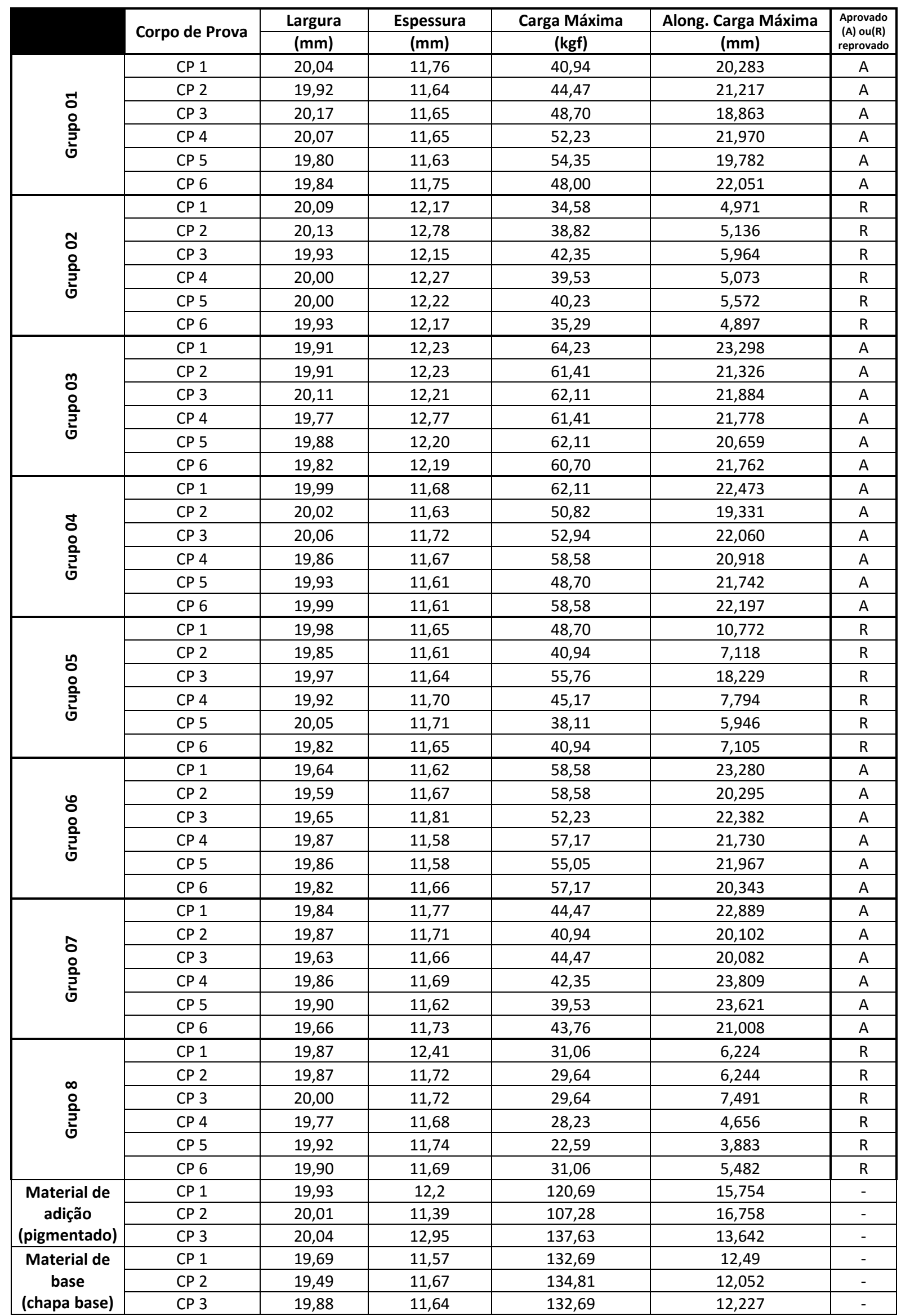




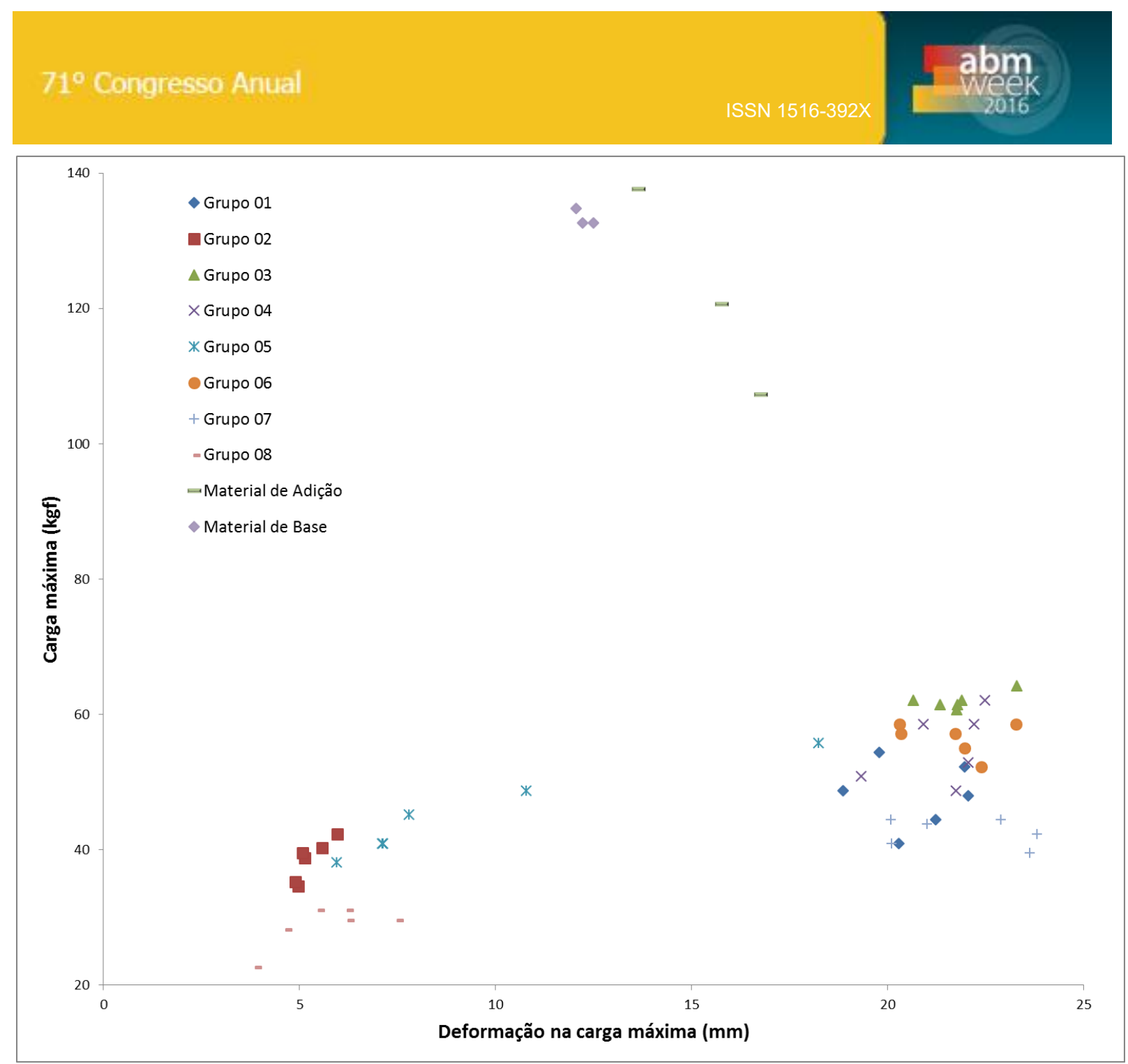

Figura 4.Gráfico carga máxima x deformação na carga máxima nos ensaios de flexão.

A Figura 4 permite identificar grandes discrepâncias de desempenho entre os grupos avaliados. O material de adição fundido com o fio pigmentado mostrou uma capacidade de carga em flexão semelhante à do material de base. Por sua vez, em comparação com os resultados obtidos com o material de base e com o fio de solda pigmentado, os cordões de solda executados apresentaram uma capacidade de carga inferior. Mesmo quando aprovados no teste, a capacidade de carga dos corpos de soldados é da ordem de 40 a $50 \%$ da capacidade do material de base.

Constatou-se que somente foram reprovadas (e romperam) as soldas realizadas com condições de baixo aporte de calor (Grupos 2, 5 e 8). A fratura ocorre na interface entre a face do chanfro e a solda propriamente dita (Figura 3).A provável explicação para este resultado é a de que o baixo aporte de calor não foi suficiente para causar a fusão necessária entre o cordão de solda e a chapa base.

As soldas sem preparação/higienização (Grupos 3 e 6) mostraram resultados de teste aprovados e com capacidade de carga até maior do que as com preparação similares (Grupos 1 e 4). No entanto, cabe ressaltar que estas soldas foram realizadas em chanfros fresados $e$, portanto, a geometria da superfície não encontrava-se degradada. A preparação/higienização da superfície do chanfro promove a remoção de material, resultando na alteração da geometria do chanfro, que, notadamente, representa outra variável essencial do processo de soldagem. 
Este efeito pode ser percebido pela grande dispersão dos resultados obtidos com os corpos de prova dos Grupos 1 e 4.

Então, em termos da preparação/higienização, é importante controlar o processo de raspagem. A raspagem das faces do chanfro pode mudar bastante sua geometria, tal como o ângulo entre as faces e seu espaçamento. Com isso, muda-se o aporte de calor necessário e a quantidade ideal de depósito de material, dentre outros fatores. Conclui-se, então, que a raspagem executada por ocasião da preparação pode alterar significativamente os parâmetros iniciais de soldagem e, consequentemente, o controle da qualidade da solda.

Quanto à presença de pigmento no fio de solda, foi possível identificar que o fio de solda natural (Grupos 1 e 3) mostrou uma maior capacidade de carga em relação ao fio de solda pigmentados (Grupos 4 e 6). Uma possível explicação para esse resultado seria a presença de aditivos de pigmentação do fio de solda, os quais comprometeriam, em parte, a resistência do cordão de solda.

Quanto à velocidade de soldagem, foi observado que mesmo com o aporte mais elevado (Grupo 8), a falta de material de enchimento levou à menor capacidade de carga, não sendo recomendável utilizar valores tão elevados.

\section{CONCLUSÕES}

Este trabalho permitiu identificar condições limite de parâmetros de soldagem por extrusão na união de chapas de PEAD, com base em critérios de aceitação recomendados internacionalmente. No decorrer deste trabalho foi constado que:

- As soldas capacidade do material, nas configurações testadas, têm capacidade da ordem de 40 a $50 \%$ da de base.

- O baixo aporte de calor ocasiona ruptura na interface chapa base/cordão de solda à baixas tensões.

- A velocidade de soldagem influencia na área seccional do cordão de solda e, consequentemente, na resistência mecânica.

- A higienização da solda implica em uma perda da qualidade mecânica da solda. Suspeita-se que o processo de raspagem da higienização resulta em uma descaracterização do chanfro, o que comprometeria a qualidade da solda.

- Há indícios de que a pigmentação da solda influencia negativamente as propriedades mecânicas do material soldado. Neste trabalho não foi possível identificar se o motivo disso é a pigmentação em si ou a interação entre a chapa base pigmentada e o cordão de solda em estado natural. Também seria necessário um estudo mais profundo para identificar a relação de pigmentação com a resistência da solda.

Apesar de que se construírem embarcações de polietileno desde 2007, poucos estudos foram feitos sobre comportamento mecânico de elementos semi-acabados de polietileno soldados por extrusão para fins estruturais. O processo de soldagem por extrusão é usado principalmente na construção de tanques e dutos, selagem de geomembranas, isolamento e união de forros [3][4]. Então, consequentemente, esse é o foco da maioria dos trabalhos acadêmicos. Já foram feitos estudos para propriedades mecânicas em chapas de $3 \mathrm{~mm}$ de espessura soldadas por ar quente (hot gas welding) [5], porém fora da realidade das construções de embarcações, que utilizam chapas mais espessas $(15 \mathrm{~mm})$ e usam majoritariamente soldas por extrusão. 


\section{Agradecimentos}

Aos profissionais da DGS Defense e da Tecmetal, que cederam o espaço, o tempo e compartilharam conhecimento para a melhor conclusão deste trabalho. Agradecimentos especiais ao Sr. Abílio di Gerardi e ao Sr. Raphael Barreto, que permitiram o acesso ao estaleiro e disponibilizaram a equipe de profissionais para a confecção dos corpos de prova, e também à Sra. Annelise Zeemann e Sr. Paulo Emygdio, que além de reservar uma parte do tempo e da equipe do laboratório, contribuíram com conselhos valiosos durante a execução dos testes.

\section{REFERÊNCIAS}

1 DVS. Technical Code DVS 2203-2. Testing of welded joints between panels and pipes made of thermoplastics - Tensile test. s.I. : DVS - Deutscher Verbandfür Schweissen und Verwandte Verfahren E.V, 2010.

2 DVS. Technical Code DVS 2207-4. Welding of thermoplastics - Extrusion welding of pipes, piping parts and panels - Processes and requirements. s.I. : DVS - Deutcher Verband für Schweissen und Verwandte E.V., 2013.

3 David Grewell, Avraham Benatar. Welding of Plastics: Fundamentals and New Developments. International polymer Processing XXII, pág. 43 a 60, 2007.

4 Fernanda Coutinho, Ivana Mello, Luiz de Santa Maria. Polietileno: Principais Tipos, Propriedades e Aplicações. Polímeros: Ciência e Tecnologia, volume 13, no 1, pág. 1 a 13, 2003.

5 Onur Balkan, Halil Demirer, Ayhan Ezdesir, Hüseyin Yildirim. Effects of Welding Procedures on Mechanical and Morphological Properties of Hot Gas Butt Welded PE, PP, and PVC Sheets.Journal of Achievements in Materials and Manufacturing Engineering. Volume 31, Issue 1, pág. 60 a 70, Novembro de 2008. 